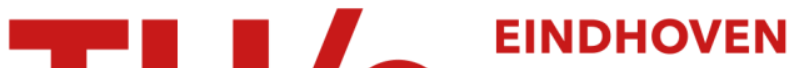 \\ UNIVERSITY OF \\ TECHNOLOGY
}

\section{Leaky wave lens antenna for wide/multi band application}

Citation for published version (APA):

Neto, A., Bruni, S., Gerini, G., \& Sabbadini, M. (2005). Leaky wave lens antenna for wide/multi band application. In Proceedings of the 2005 European Microwave Conference, EuMC 2005, 4-6 October 2005, Paris, France

(Vol. 3, pp. 1-4). Institute of Electrical and Electronics Engineers. https://doi.org/10.1109/EUMC.2005.1610320

DOI:

10.1109/EUMC.2005.1610320

Document status and date:

Published: 01/01/2005

\section{Document Version:}

Publisher's PDF, also known as Version of Record (includes final page, issue and volume numbers)

\section{Please check the document version of this publication:}

- A submitted manuscript is the version of the article upon submission and before peer-review. There can be important differences between the submitted version and the official published version of record. People interested in the research are advised to contact the author for the final version of the publication, or visit the $\mathrm{DOI}$ to the publisher's website.

- The final author version and the galley proof are versions of the publication after peer review.

- The final published version features the final layout of the paper including the volume, issue and page numbers.

Link to publication

\section{General rights}

Copyright and moral rights for the publications made accessible in the public portal are retained by the authors and/or other copyright owners and it is a condition of accessing publications that users recognise and abide by the legal requirements associated with these rights.

- Users may download and print one copy of any publication from the public portal for the purpose of private study or research.

- You may not further distribute the material or use it for any profit-making activity or commercial gain

- You may freely distribute the URL identifying the publication in the public portal.

If the publication is distributed under the terms of Article 25fa of the Dutch Copyright Act, indicated by the "Taverne" license above, please follow below link for the End User Agreement:

www.tue.nl/taverne

Take down policy

If you believe that this document breaches copyright please contact us at:

openaccess@tue.nl

providing details and we will investigate your claim. 


\title{
Leaky Wave Lens Antenna for Wide/Multi Band Application
}

\author{
A. Neto ${ }^{1}$, S. Bruni ${ }^{1,2}$, G. Gerini ${ }^{1}$, M. Sabbadini ${ }^{3}$, \\ ${ }^{1}$ TNO Defence, Security and Safety, \\ Den Haag 2597 AK, The Netherlands. \\ E-mail: andrea.neto, simona.bruni, giampiero.gerini@ tno.nl. \\ ${ }^{2}$ Department of Information Engineering, University of Siena, 53100, Siena, Italy. E-mail: bruni@ dii.unisi.it \\ ${ }^{3}$ European Space Research and Technology Center (ESTEC), \\ 2200 AG Noordwijk, The Netherlands. E-mail: Marco.Sabbadini@esa.int
}

\begin{abstract}
A novel type of leaky wave antenna is presented. Differently from previously reported leaky wave antennas, it is based on a radiation phenomenon which is intrinsically wide band. The antenna is designed to be an integrated receiver that is compatible with manufacturing technologies in the sub-mm wave ranges. However in order to provide a preliminary proof of concept two scaled models have been designed, manufactured and tested. One is broad band with operational frequencies between 10 and $20 \mathrm{GHz}$. The second is dual band operating at $10.5 \mathrm{GHz}$ and $22.5 \mathrm{GHz}$ with $43 \%$ and $19 \%$ bandwidths. The measurements are in very good agreement with the expectations, demonstrating the potentials of the leaky lens concept to realize integrated transmitters or receivers that are extremely broad band and directive. The ranges of applications are not restricted to sub-mm wave operations for which it was conceived. A joint TNO-ESTEC patent is pending on this type of antennas.
\end{abstract}

\section{INTRODUCTION}

Leaky wave antennas have been investigated for a long time [1, and there cited references] and are typically an inexpensive solution for beam scanning antennas. Indeed, since most types of leaky propagation mechanisms are very dispersive, the beam direction can be scanned with frequency, provided one accepts a narrow bandwidth available for each scanning angle. In [2], [3] and [4] the Green's Function (GF) of a slot printed between two infinite dielectrics, (Fig. 1), has been investigated. This

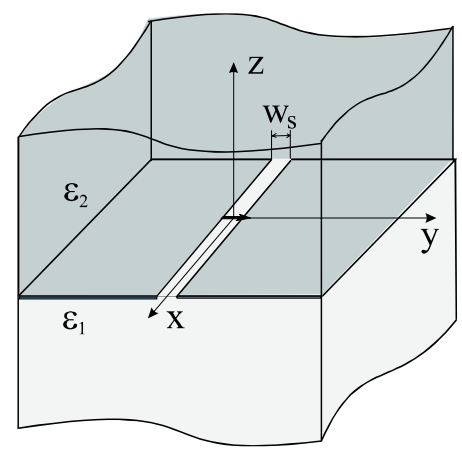

Fig. 1. Geometry of the infinitely extended s.e.d. fed slot between two semi-infinite dielectrics.

GF is characterized by a leaky-wave type radiation and by very low dispersion. It is intuitive that if a wave propagates at the interface between two different dielectrics, it travels with a phase constant, $\beta$, which is roughly the average of the ones associated to each of the homogeneous media separately. Accordingly, $\beta$ is a slow wave for the less dense medium and a fast wave (leaky) for the denser medium. If the two media are free space and a dense dielectric, radiation occurs in the dielectric. This type of propagation does not involve multiple reflections due to a finite thickness slab, or to a waveguide type of cross section; which typically render dispersive all previously proposed leaky wave radiation mechanisms.

In the frame of an ESA-ESTEC contract, performed together with Satimo and Saab-Ericsson Space, these properties have been explored for the design of two leaky wave antennas: a wide-band antenna and a multi-band antenna. In particular, the design has been tailored to the realization of antennas that could be used as directive feeds for sub-mm wave applications, which is a field where integrated lens antennas are often used [5], [6]. The chosen sub-mm wave environment should not be seen as bounding the ranges of applications, in fact the prototypes manufactured have been scaled to operate in the micro-wave region and their performances are very satisfactory.

\section{ANTENNA DESCRIPTION}

The slot in Fig. 1, rather than behaving as a transmission line, behaves as a leaky wave antenna. Most of the characteristics of such a structure have been described analytically [2], [3]. For small width $\left(w_{s}\right)$ in terms of the wavelength, its properties are dominated by the asymptotic value of the complex propagation constant along the slot

$$
k_{x}^{L W} \approx \beta+\frac{k_{d}^{2}}{2 \beta\left[1-j \frac{4}{\pi} \ln \left(\gamma_{e} k_{d} \frac{w_{s}}{8}\right)\right]}
$$

where $\gamma_{e}=1.781 \ldots$ is the Euler constant, $k_{d}=\sqrt{\frac{k_{2}^{2}-k_{1}^{2}}{2}}$, $\beta=\sqrt{\frac{k_{2}^{2}+k_{1}^{2}}{2}}, k_{i}=k_{0} \sqrt{\epsilon_{r i}}$ with $i=1,2$ and $k_{0}$ is the free space propagation constant. From the leaky wave propagation constant in (1) one immediately verifies that the phase velocity of the slot varies very little with the frequency since the first order variations as a function of the frequency tends to alter only the imaginary part (attenuation) of the propagation constant. Thus the direction of the main beam is essentially frequency independent. However, it is apparent that the canonical geometry in Fig. 1 is unrealistic for two reasons

- infinitely long slots do not exist

- infinite homogeneous dielectrics with $\epsilon_{r i} \neq 1$ do not exist. 
The length of a realizable slot is necessarily finite. However, since the leaky wave that propagates along the slot radiates power in the dielectric, at certain distance from the feed point the amount of power still carried by the wave is negligible. At that point the structure can be terminated without causing significant reflections from the end-point. Accordingly, using (1), it is possible to determinate a priori the minimal length of the slot that would not significantly impact the radiation properties of the ideal structure (Fig. 1).The radiation pattern inside the dielectric of the ideal slot structure presents two beams since leaky waves are launched from the feed in the two opposite directions of the slot. In order to obtain a unique beam one can close one of the two arms of the slot line in a short circuit located at $\lambda_{e} / 4$ (being $\lambda_{e}=\frac{2 \pi}{\beta}$ the effective wavelength in the slot) from the location of the feed.

The second hypothesis, infinite homogeneous dielectrics is crucial to the low dispersion properties of the slot. Indeed most printed leaky structures present strong dispersivity because of finite slabs thicknesses that give rise to reflections at the dielectric air interface. These reflections cannot occur in the geometry represented in Fig. 1 but they will occur whenever the dielectric is finite. However, when the dielectric lenses are elliptical and rotationally symmetric, and the sources are located in one of the two foci the dielectric is typically approximated as infinite. The impact of the finite dimension of the dielectric lens has been considered for lenses of elliptical profile [7], that were fed by resonant elements. It has resulted that the alterations of the input impedance are always less than $10 \%$ of the nominal (unperturbed value) even for typically dense dielectrics (silicon). This is because, as explained in [7] all the rays emanated from a source located in a focus undergo at least two reflections and pass through the second focus before returning coherently on the original focus.

In the present long slot case, a ray picture can be associated to the radiation from the slot in the infinite dielectric. This was widely discussed in [3]. Such rays are launched by the slot to form an angle $\gamma$ with the slot axis. $\gamma$ is only function of the dielectric discontinuity $\left(\epsilon_{r 1}, \epsilon_{r 2}\right)$ and can be expressed by

$$
\gamma \approx \cos ^{-1} \sqrt{\frac{\epsilon_{r 1}+\epsilon_{r 2}}{2 \epsilon_{r 2}}}
$$

By shaping the lens as in Fig. 2, one can obtain that the ray emanating from each point in the slot undergo a double reflection mechanism that simulates the one observed [7] in rotationally symmetric lenses. The shape is obtained as union of an infinite set of cross section planes of elliptical shape and decreasing dimension. The ellipses contain the slot in their lower focus. Fig. 2 explicitly shows the elliptical cross sections and also depicts the rays a) emanated from the slot (lower focus), b) transmitted after the first interface (focus effect in the far field), c) reflected at the first interface, d) transmitted at the second interface (unfocused), e) reflected at the second interface and refocused toward the lower focus. For the sake of convenience the origin of the reference system in Fig. 2 is located in correspondence of the short circuit closer to the feeding point of the slot. This reference system defines the first ellipse cut (see the inset), which actually bounds the maximum dimension of the lens. The choice of cutting the lens in correspondence of the first ellipse cut, minimizes the frequency dependent interference between the leaky rays passing through the bulk of the lens and rays diffracted at the highest point of the first ellipse cut. One can further specify that the rays impinge normally to the dielectric air interface in the $H$-plane (plane parallel to the slot and orthogonal to the ground plane). This characteristic is imposed only for the sake of rendering more intuitive the behavior of the lens maintaining, in the $H$-plane, the beam outside the lens parallel to the rays leaving the slot inside the dielectric.
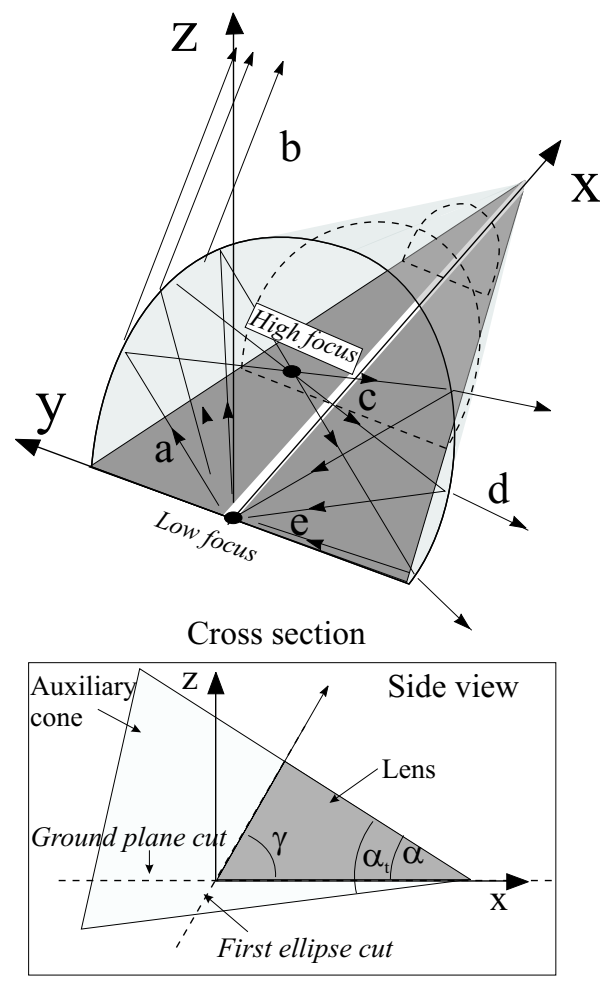

Fig. 2. 3-D view of the lens and frequency independent ray mechanisms.

It is interesting to observe that the dielectric lens can be obtained as a portion of a dielectric cone of tip angle $\alpha_{t}$ (Fig. 2 side view). The portion is obtained by introducing two cutting planes. The first plane (ground plane cut) passes through the tip in such a way that, in the $x-z$ plane, the ground plane and the line of the dielectric cone at further distance from the $x$ axis form an angle $\alpha$. The actual value of the angles $\alpha_{t}$ and $\alpha$ are only functions of the dielectric constant, since $\epsilon_{r 1}=1$

$$
\alpha_{t}=t g^{-1}\left(\frac{2 \sqrt{\epsilon_{r 2}}}{\sqrt{\epsilon_{r 2}}+1} \operatorname{tg} \alpha\right)
$$

where $\alpha=\frac{\pi}{2}-\gamma$ and $\gamma=\cos ^{-1}\left(\sqrt{\frac{\epsilon_{r 2}+1}{2 \epsilon_{r 2}}}\right)$.

It is important to note that the use of the elliptical cross sections not only renders applicable the analysis results pertinent to slots etched between two infinite dielectrics, but also maximizes the directivity in the $E$-plane. The directivity in the $H$-plane is instead achieved only thanks to the leakage effects.

In the frame of an ESA contract, two antennas have actually been designed and manufactured. The first antenna was designed to operate over a wide band while the second one was to be excited by two feeds points and operate in two narrower frequency bands. The only two parameters that needed to be independently decided to design these antennas, were the dielectric constant and the slot's width. The smaller is the slot's width, in terms of the effective wavelength, the lower 
is the attenuation constant and consequently the higher is the directivity. Given that the minimal slot's width, dictated by the fabrication accuracies of the TNO internal workshop, was 0.1 $\mathrm{mm}$, it was decided to use a $0.2 \mathrm{~mm}$ wide slot. This choice together, with a commercially available low loss dielectric material $\left(\epsilon_{r 2}=3.27\right.$ from Rogers $)$ guarantees a sufficiently long slot to obtain the desiderated directivity and minimize the reflections at the dielectric air interface. The length of the slot has been fixed to $120 \mathrm{~mm}$, in order to make acceptable, also in the X-band, the impact of the reflections occurring at the far end of the slot. In conclusion, given that the wave mechanisms in the slot and in the lens are essentially frequency independent, the basic lens and slot design is a very simple and straight forward task. The only differences between the two antennas arise from the feeding arrangements. In both cases the feeding of the slot is realized via coplanar waveguide $(\mathrm{CPW})$ lines. For ease of the testing the two realized antenna prototypes operate at relatively low frequencies and the CPW lines have been connected to coaxial cable.

\section{Measurement Results}

\section{A. Wide Band Antenna}

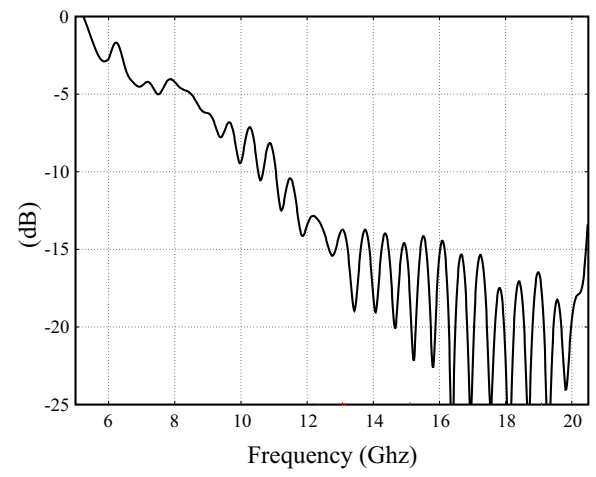

Fig. 3. $S$ parameters for the wide band design operating from 10 to $20 \mathrm{GHz}$.

The wide band antenna has been designed to operate at a central frequency of $15 \mathrm{GHz}$. The measured $S_{11}$ parameter, normalized to $50 \Omega$, is presented in Fig. 3. The $S_{11}$ parameter is below the $-10 \mathrm{~dB}$ from $12 \mathrm{GHz}$ to $20 \mathrm{GHz}$. The small period oscillations are associated to double reflections at the lens-air interface [7].

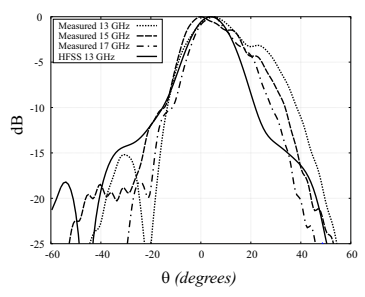

(a)

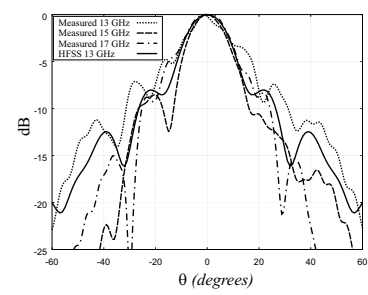

(b)
Fig. 4. Radiation pattern for the wide band design: (a) E-Plane; (b) $H$-Plane.

The radiation patterns of the wide band antenna have been measured in the range from $13 \mathrm{GHz}$ to $17 \mathrm{GHz}$. The antenna pattern has a pointing angle essentially constant and its $-3 \mathrm{~dB}$ angle shows a limited variation over a large bandwidth. This antenna is probably the first one to present such property among leaky wave antennas. The measured directivities are reported in Table I. The directivity calculated at $13 \mathrm{GHz}$, using HFSS is also reported and it is in very good agreement with the measured one. One can note that the directivity increases very moderately over the investigated frequency range.

\begin{tabular}{|c|c|}
\hline Frequency $(\mathrm{GHz})$ & Measured Directivity $(\mathrm{dB})$ \\
\hline 13 & $17.389(17.6$ HFSS $)$ \\
\hline 14 & 18.446 \\
\hline 15 & 18.216 \\
\hline 16 & 18.834 \\
\hline 17 & 19.169 \\
\hline
\end{tabular}

TABLE I

MEASURED DiRECTIVITY.

The normalized measured radiation patterns at 3 frequencies $(13,15$ and $17 \mathrm{GHz})$ of the wide band antenna are presented in Fig. 4(a) ( $E$-plane) and Fig. 4(b) ( $H$-plane). The $E$-plane pattern is fairly symmetric and if one concentrates on the $-3 \mathrm{~dB}$ radiation it varies from 18 degrees to 16 degrees in the considered frequency range, maintaining the same pointing angle. The same cannot be said for $H$-plane due to the frequency dependent focusing effect of the lens. In this case the $-3 \mathrm{~dB}$ beamwidth shows a variation from 18 to 25 degrees. In the same figure, for both $E$ - and $H$-plane, we also report the radiation patterns calculated by means of HFSS (at $13 \mathrm{GHz}$ only). These show a good agreement with the measurement. No real optimization of the radiation pattern has been performed due to limitations in the available modelling tools. The design has been based on intuition and frequency independent considerations only, therefore these results should be regarded as extremely encouraging.

\section{B. Dual Band Antenna}

For the dual band antenna it has been decided to choose a frequency ratio approximately 1 to 2 . The restriction to two operation frequencies is just for the sake of simplicity in the design of the filtering structure needed to isolate the two feeding points. Indeed there is no intrinsic limitation in the proposed design preventing the use over an arbitrary set of central frequencies. The dual band prototype has been manufactured and tested after the wide band version and therefore it benefits of the experience gained with the first one. The two central frequencies are $10.5 \mathrm{GHz}$ and $22.5 \mathrm{GHz}$ respectively. The measured $S$ parameters in a band from 5 to $30 \mathrm{GHz}$ are reported in figures 5 (a) ( $S_{11}$ parameters), (b) ( $S_{12}$ parameters) and (c) $\left(S_{22}\right.$ parameters). In all three figures the measured data (solid lines) is compared directly with the calculated data (dashed lines) from Ansoft Designer. Each one of the channels has a very broad band which is restricted only by the isolating stubs adopted in the filtering feed structure. Assuming $-13 \mathrm{~dB}$ as maximum acceptable levels for the reflection $\left(S_{11}\right)$ and the isolation $\left(S_{12}\right)$ parameters, the following bandwidths can be observed: from $9 \mathrm{GHz}$ to $14 \mathrm{GHz}$ for the lower frequency (43\%) and from 20 to $25 \mathrm{GHz}(19 \%)$ for the higher frequency. The agreement between measured and calculated $S$ parameters is outstanding. This is remarkable, especially considering that for this dual band antenna the time gating to extract the coax to CPW transition was not used. The oscillation of relatively large 


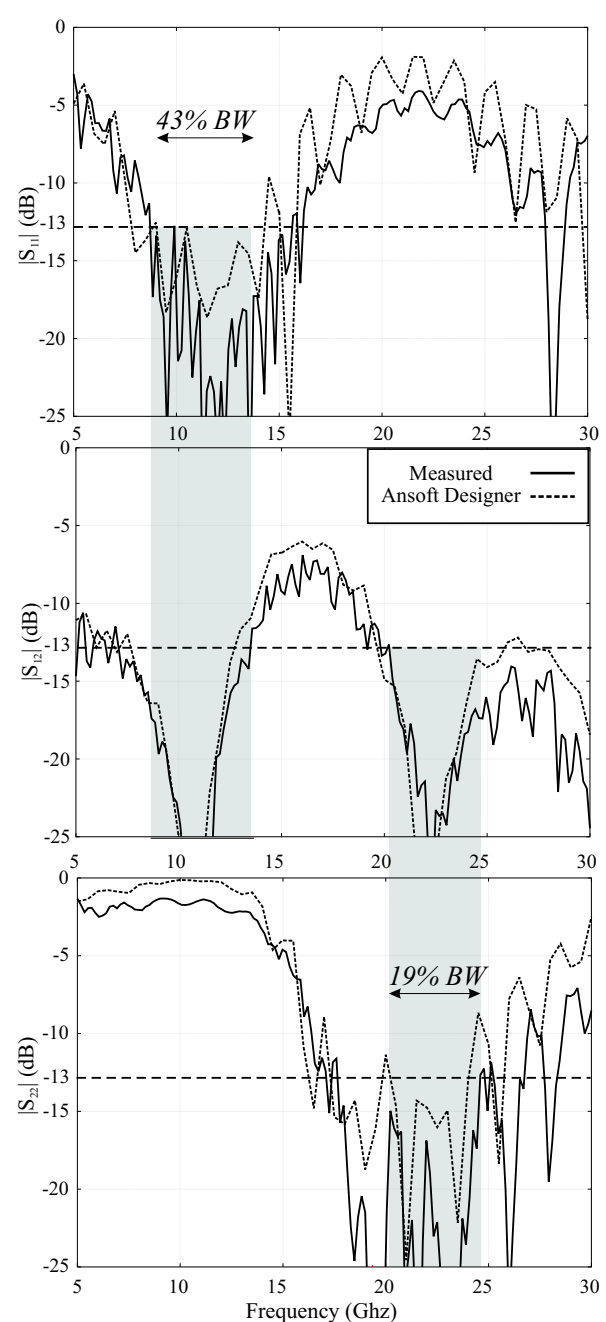

Fig. 5. $S$ parameters for the dual band design: measured (solid lines) and simulated (dashed lines). $43 \%$ and $19 \%$ relative bandwidth at $-13 \mathrm{~dB}$ level can be observed.

period reported in the calculations and in the measurements are due to mismatches between the coax to CPW transition caused by the dispersive behavior of the CPW. This oscillations could be avoided by decreasing the minimal slot's width to 0.05 $\mathrm{mm}$ or using an integrated receiver characterized by higher impedance or using microstrip type of feeding. The oscillations of smaller period, observed in the measurement only, are the effect of the reflections at the dielectric interface.

The measured radiated fields at $10.5 \mathrm{GHz}$ and $22.5 \mathrm{GHz}$ are reported in figure 6 . The radiated fields in both $E$ and $H$ planes are shown. In the $H$-plane the maximum radiated field at $22.5 \mathrm{GHz}$ is shifted of 3.5 degrees with respect to the one at $10.5 \mathrm{Ghz}$. This shift is small compared to beamwidth and essentially due to a slight asymmetry of the beam rather than to a depointing.

\section{CONCLUSION}

A novel broad-band and directive leaky wave antenna has been presented. The unique feature of this antenna is that its main beam of radiation remains substantially the same at different frequencies. To our knowledge a leaky wave antenna whose pointing angle is essentially constant and with limited variation of the $-3 \mathrm{~dB}$ angle over a significant frequency sweep

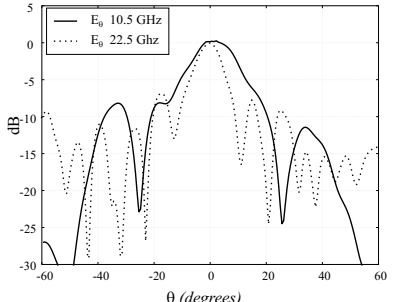

(a)

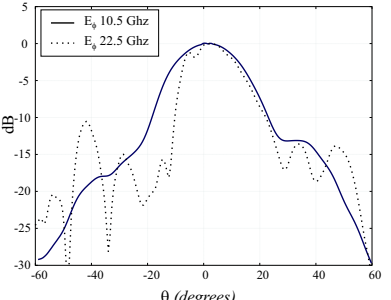

(b)
Fig. 6. Comparison between the radiation patterns at $10.5 \mathrm{GHz}$ and 22.5 $\mathrm{GHz}$ (a) E-Plane; (b) $H$-Plane.

(one octave) has never been reported before. This is due to the peculiar radiation mechanism that has found here its first application. Two prototypes have been designed, manufactured and measured. The agreement between measurements and calculations proves the repeatability of the design, which is in large part based on basic, frequency independent, physical concepts.

The performances of this leaky wave lens antenna are comparable to those of long tapered slot (LTS) antennas [8]. With respect to LTS antennas they present significantly broader bandwidths, however they require a dielectric lens which makes them bulky at low frequencies. The directivity is such that the system can be used both as a self standing integrated receiver or as feed of a reflector system.

\section{REFERENCES}

[1] F. Mesa, A.A. Oliner, D.R. Jackson, M.J. Freire, "The influence of a top cover on the leakage from microstrip line", IEEE Transactions on Microwave Theory and Techniques, Vol. 48, no. 12, pp. 2240-2248 Dec. 2000.

[2] A. Neto and S. Maci, "Green's Function of an Infinite Slot Printed Between Two Homogeneous Dielectrics. Part I: Magnetic Currents", IEEE Transactions on Antennas and Propagation, Vol. 51, no. 7, pp. 1572-1581 July 2003

[3] S. Maci and A. Neto, "Green's function of an infinite slot line printed between two homogeneous dielectrics. Part II: Uniform asymptotic fields", IEEE Transactions on Antennas and Propagation, Vol. 52, no. 3, pp. 666-676, March 2004.

[4] A. Neto and S. Maci, "Input Impedance of Slots Printed Between Two Dielectric Media and Fed by a Small $\triangle$-gap", IEEE Antennas and Wireless Propagation Letters, Vol. 3, no. 7 , pp. 113-116, 2004.

[5] D. F. Filippovic, S. S. Gearhart and G. M. Rebeiz, "Double Slot on Extended Hemispherical and Elliptical Silicon Dielectric Lenses", IEEE Transactions on Microwave Theory Techiques, Vol. 41, no. 10, October 1993.

[6] P.H. Siegel, "Terahertz technology ", IEEE Transactions on Microwave Theory and Techniques, Vol. 50, no. 3 , pp. 910-928, March 2002.

[7] A. Neto, S. Maci and P. J. de Maagt, "Reflections inside an elliptical dielectric lens antenna”, IEE Proc. Microwaves, Antennas and Propagation, June 1998.

[8] J. B. Muldavin, G.M. Rebeiz, "Millimeter-wave tapered-slot antennas on synthesized low permittivity substrates", IEEE Transactions on Antennas and Propagation, Vol. 47, no. 8, pp. 1276-1280, August 1999. 